\title{
El marco normativo de los acuerdos colectivos no cubre las expectativas
} negociales de los empleados públicos sindicalizados*

\section{The regulatory framework of collective agreements does not cover the bargaining expectations of unionized state employees}

\author{
Silvio León Castaño**
}

\begin{abstract}
*El ensayo es el producto de la investigación que se hizo con respecto a la validez y eficacia de los acuerdos colectivos de la CRQ en los últimos cinco años.

**Abogado, Magister en derecho público. Miembro del departamento de investigación de derecho público de la Univ. La Gran Colombia seccional Armenia. Autor de los libros "Manual para el Control Electoral" y "La Transición en el Régimen de Pensiones". Actualmente abogado consultor. Correo electrónico silvioleoncastano@yahoo.com Armenia, Quindío, Colombia.
\end{abstract}

Cómo citar: León, C. (2018) El marco normativo de los acuerdos colectivos no cubre las expectativas negociales de los empleados públicos sindicalizados. Inciso, 20(2); 56-74.

Recibido: 10/08/2018 Revisado: 23/10/2018 Aceptado: 10/12/2018

DOl: http://dx.doi.org/ 10.18634/incj.20v.2i.895

\section{Resumen}

Con este artículo se pretende demostrar que los acuerdos colectivos tienen demasiadas restricciones de orden constitucional y legal para garantizar la participación activa de los empleados públicos en sus condiciones de trabajo. Para ello, se trae a colación la definición constitucional del concepto de negociación colectiva, los contenidos de los convenios 151 y 154 de la OIT, y diferentes sentencias de la Corte Constitucional y el Consejo de Estado que tienden a mantener esas limitantes negociales. Como premisa fáctica se describe el contenido de las condiciones de empleo confeccionadas unilateralmente por la Procuraduría General de la Nación y el Ministerio de Relaciones Exteriores, y las interpretaciones restrictivas que hacen las altas cortes y la función pública al régimen de estímulos e incentivos.

Palabras Clave: Acuerdo colectivo, convención colectiva, constitucionalidad, estímulos para el empleado público
This article aims to demonstrate that collective agreements have too many constitutional and legal restrictions to guarantee the active participation of state employees in their working conditions. To this purpose, there are mentioned the constitutional definition of the concept of collective bargaining, the contents of ILO conventions 151 and 154, and different judgments of the Constitutional Court and the Council of State, which tend to maintain these negotiating limitations. As a factual premise, there are described the content of employment conditions unilaterally prepared by the Attorney General's Office and the Ministry of Foreign Affairs, and the restrictive interpretations made by the high courts and the public function to the regime of incentives.

Key Words: Collective agreement, collective convention, constitutionality, incentives for public employees 


\section{Introducción}

La negociación colectiva según Núñez (2016) surge por la influencia que generan las nuevas formas de trabajo y producción a partir de la revolución industrial. La Trade Unions de Gran Bretaña, las asociaciones de educación obrera alemana, las mutuales francesas, y la OIT como organización internacional vinculante, terminan por posicionar el reconocimiento jurídico del sindicalismo.

En Colombia, la ley 78 de 1919 intenta proteger el derecho de huelga, la ley 21 de 1920 estipula las condiciones de ilegalidad de la huelga. La ley 83 de 1931 estableció penas para los patronos (hoy empleadores) que atenten contra la libertad sindical. La ley 6 de 1945 reconoce el derecho de asociación, y el código de trabajo vigente regula lo concerniente al derecho a la negociación colectiva pero muy limitada para los empleados públicos (En Guerrero, 2005).

El decreto 160 de 2014 es un avance a la negociación con empleados públicos, pero como el artículo 55 de la Constitución Política permite al legislador restringir la misma -y en igual sentido los convenios 154 y 151 de la OIT- los acuerdos colectivos pueden terminan en prosa muerta pues su cumplimiento está subordinado a decisiones unilaterales de la administración pública.

El teatro español del siglo XIV en adelante entendió el sainete como una obra breve que se presentaba en el intermedio de obras de teatro, con un contenido sentimental y crítico hacia el contexto social. Eso parece ser la negociación colectiva del empleado público. Una discusión sobre temas muy limitados que anteceden las decisiones unilaterales de la administración pública, la que en últimas es quien decide vincularlas o no a las políticas legislativas, económicas y sociales.
Se realizará por lo demás, una investigación configuracional en donde el investigador involucra sus ideologías en el objeto de estudio. Se utilizan datos empíricos tomados de los acuerdos colectivos de varias entidades estatales y se realiza una investigación cualitativa.

El Configuracionismo (Ortiz, 2015) es una epistemología de las ciencias sociales que no estudia el objeto como lo hacía la ciencia tradicional, esto es, de manera aislada; por el contrario, conecta los fenómenos, eventos y procesos, en los que participan las emociones y racionalidad de los sujetos con las creaciones y tecnologías. Las hipótesis en esta nueva epistemología no se confirman ni se demuestran: se argumentan.

Los científicos reduccionistas consideran que todo es átomos y moléculas, por tanto, las leyes que explican la realidad se reducen a la física y a la química. La configuración, en cambio, no es cuantitativa (paradigma positivista) es cualitativa, pero también puede usar métodos cuantitativos. Es el espacio psíquico y el ambiente sociocultural en constante cambio. No se trata de tomar datos empíricos para construir la teoría de manera racional. En esta nueva epistemología el observador modifica lo observado gracias a sus emociones. Ya no es posible la lógica ni la verificación empírica propias del positivismo científico.

\section{No todo principio constitucional es derecho fundamental}

La Corte Constitucional al estudiar la exequibilidad del artículo 4 de la ley 153 de 1887 a través de la sentencia C-284 del 13 de mayo de 2015, dilucidó el entendimiento que se debe dar al artículo 230 inciso segundo de la Constitución Política.

Básicamente se dice que existen unos principios relacionados en el artículo 230 inciso segundo 
de la CP que no son los principios de los que se habla para indicar los contenidos del derecho en valores, principios y reglas. Pues mientras que estos principios se entienden como máximas o normas cargadas de contenidos valorativos positivados en la Constitución Política como derechos fundamentales, lo que incluye todo derecho humano que cumpla los cometidos del artículo 93, los principios de los que habla el artículo 230 inciso segundo de la CP hacen relación a normas valorativas que no han sido incorporadas conforme a los arts. 93 y 214 de la $\mathrm{CP}$, debiendo ser entendidos como derecho natural, sea teológico o racional. En cuanto a los principios generales del derecho de los que habló "la corte de oro" de mediado de los años 30 , en realidad son analogía iuris, pues son reglas extraídas del querer del legislador, lo que los convierte en derecho positivo vinculante.

Como corolario se tiene lo ya afirmado en otras publicaciones con respecto a los requisitos exigidos para incorporar principios extrasistémicos:

Los principios que no fungen como fundamentales, en cambio, pueden ser: i) positivos, como los contenidos en el artículo 53 de la Constitución Política y son vinculantes para el juez; o ii) extra sistémicos o generales, como los que surgen de un proceso de inferencia y son supletorios, art 230-2 C.P.

Los principios positivos que no fungen como derechos fundamentales y responden a derechos subjetivos de tipo patrimonial o pragmático, incluso morales, y -aunque se positivizan- pueden ser soslayados totalmente en casos determinados ante la presencia de supuestos de hecho de otras normas. Tal es el caso del principio de la progresividad que no es absoluto y puede ser desconocido si se trata de proteger otro derecho fundamental; si el desconocimiento no es permanente; o si los recursos económicos no permiten seguir cubriendo necesidades insatisfechas en la proporción establecida, con lo que se prioriza la continuidad de otros fines estatales en un momento histórico determinado. (León, pág. $61)$.

\section{El derecho de sindicación y asociación en la Constitución Política de 1991}

La Constitución Política colombiana señala que toda persona tiene derecho a reunirse de manera momentánea, pacífica y pública. De esas reuniones pueden surgir asociaciones permanentes de todo tipo, unas con fines lucrativos, otras sin ánimo de lucro, como los sindicatos, arts. 37 y 38 .

La autonomía privada o facultad que tienen las personas para autorregular sus intereses o darse normas de conducta y que nace con las revoluciones liberales, es también el fundamento de la libertad de asociación con fines laborales.

El constituyente a través del artículo 39 definió como núcleo esencial del derecho de libertad sindical, el derecho a constituir asociaciones de trabajadores y empleadores y, especialmente, el derecho a la negociación colectiva en aras de lograr el mejoramiento de las condiciones de trabajo. El derecho a la sindicación lo entiende además desde una dimensión individual y otra colectiva o relacional que le permite a la persona desarrollar libremente su personalidad y sus proyectos de vida.

Como garantía a esa libertad de conducta, el constituyente preceptuó que los sindicatos adquieren personería jurídica por el solo hecho de reunirse con tal fin. Le prohibió al Estado realizar injerencias en la conformación de los estatutos de la entidad; le permite a los sindicatos nombrar como negociadores a personas ajenas al sindicato; igualó los derechos de los trabajadores extranjeros con los derechos de los trabajadores nacionales en materia de negociación colectiva y pertenencia a las juntas directivas de los 
sindicatos; a nivel legal permitió que las personas pertenezcan a varios sindicatos al mismo tiempo una vez cumplan los 14 años de edad -art 35 de la ley 1098 y 383 CST- pudiéndose beneficiar eso sí de un solo acuerdo o convención colectiva; y, ante todo, el derecho que tienen los sindicatos a no ser disueltos y liquidados y cancelada su personería jurídica sino por decisión judicial y por causas taxativas, arts. 353 a 372 del CST.

Al respecto dijo la Corte Constitucional en la sentencia C-466 de 2008, ratificando anteriores sentencias, lo siguiente:

Considera la Corte, en consecuencia, que la libertad sindical comporta: i) el derecho de todos los trabajadores, sin discriminación ni distinción alguna, para agruparse a través de la constitución de organizaciones permanentes que los identifican como grupos con intereses comunes, y cuya defensa propugnan. Este derecho implica la libertad tanto para afiliarse como para retirarse de dichas organizaciones;

iv) La facultad de las asociaciones sindicales para formular las reglas relativas a la organización de su administración, así como las políticas, planes y programas de acción que mejor convengan a sus intereses, con la señalada limitación; v) la garantía de que las organizaciones de trabajadores no están sujetas a que la cancelación o la suspensión de la personería jurídica sea ordenada por la autoridad administrativa, sino por vía judicial; vi) el derecho de las organizaciones sindicales para constituir y afiliarse a federaciones y confederaciones nacionales e internacionales; vii) la inhibición, para las autoridades públicas, incluyendo al legislador, de adoptar regulaciones, decisiones o adelantar acciones que tiendan a obstaculizar el disfrute del derecho a la libertad sindical.

Pero esa libertad sindical, como derecho fundamental, tiene límites que le impiden maximizarse en la mayor medida posible tales como la realidad económica y social, y la existencia de otros principios y valores igualmente valiosos como la estabilidad financiera del sistema.

El pluralismo jurídico reconocido en el artículo primero de la Constitución Política y el derecho a participar en las cosas que nos incumben, valor fundante y principio consagrado expresamente en el preámbulo y en el artículo primero constitucional, implican la superación del Estado como único creador del derecho, pero genera grandes posibilidades de colisión de los principios positivados fruto de esa diversidad valorativa reconocida en el texto constitucional.

Compete entonces al legislador y al juez constitucional ponderar ante las diferentes fricciones priorizando un principio en casos determinados sin desconocer en todo caso el núcleo esencial del principio que sale derrotado.

Eso, precisamente eso, es lo que permite afirmar que el derecho a la negociación colectiva no es absoluto, tiene límites que deben ser definidos por el legislador, quien -en todo casodebe respetar no solo los procedimientos de confección de esas reglas, sino el contenido de la principialistica desarrollada de manera expresa por el bloque de constitucionalidad, arts. 241-4, 93, 214, además del respeto por todo derecho humano que desarrolle contenidos pro hómine.

No obstante existir en la norma constitucional el principio según el cual no existen normas pétreas, por lo que es viable modificar los derechos fundamentales, art 377 y 241-1, entre ellos el derecho a la libertad sindical, no puede en todo caso sustituirse el eje axial o elementos definitorios que le dan identidad a la Constitución Política, EDIC.

Habiendo entendido la Corte Constitucional que en Colombia existe una rigidez específica con una resistencia constitucional relativa en cuanto 
a los cambios, pues no existen normas pétreas que le impidan a la carta magna adaptarse a los nuevos requerimientos de la vida de relación, construyó una metodología a través de lo que llamó el juicio de sustitución que permite en determinado momento estudiar si una ley o una decisión administrativa vulnera el eje axial.

Para realizar el juicio -dice la corte- se debe: i) acudir a los principios y valores constitucionales y del bloque de constitucionalidad; ii) a la doctrina constitucional y política; iii) a las experiencias de otros países con modelos constitucionales similares; $y, i v)$ a la jurisprudencia constitucional.

Hay sustitución según la corte a propósito del proceso de paz según la C-332/17:

1. Si se modifica el modelo democrático por un modelo autoritario o por una monarquía.

2. Si se suprime la separación de poderes, o el ser una República unitaria en cuanto a la justicia y la legislación, descentralizada, con autonomía territorial, participativa, pluralista, presidencial y con supremacía de la Constitución Política.

3. Si no se respeta el concurso público como principio para acceder en igualdad de condiciones a los cargos públicos.

4. Si se hace nugatoria la alternancia en el poder como mecanismo para proteger a las minorías. Principio constitucional soslayado con el acceso al poder presidencial de las mismas familias, lo que implica que en las cosas importantes de política de Estado sea un grupo muy pequeño el que ha definido y define los objetivos sociales, económicos y políticos, como las condiciones de empleo, quedando en la mayoría de la población la participación en las cosas de menor importancia.

5. Igualmente no se puede sustituir la soberanía popular, la democracia participativa, la efectividad del voto, por lo que la doble militancia y el transfuguismo vulneran esos principios. De allí la importancia de sancionar las conductas que vulneran la confianza legítima del elector en aras de intereses egoístas del elegido, protegiéndose con ello la moralidad pública y la prevalencia del interés general, el deber de los congresistas de actuar en procura de la justicia y el bien común, y la posibilidad de que los electores controlen la actuación de los elegidos

6. Y, cuando se suprimen las competencias a uno de los órganos del poder público y se trasladan a otra rama del poder público.

De las enunciaciones que ha hecho la Corte Constitucional en precedencia -textos abiertos a la espera de seguir siendo interpretados y ampliados en la medida en que ello beneficia al hombre- el derecho a la participación en las cosas que nos incumben hace parte del eje axial y allí precisamente se acoraza el derecho de asociación y libertad sindical, por lo que las limitaciones al mismo requieren de una mayor carga argumentativa.

\section{El bloque de constitucionalidad y la negociación colectiva}

Elbloque de constitucionalidad sirve para estudiar la validez de las leyes y su correspondencia con el ordenamiento constitucional. Los tratados de derechos aprobados conforme a las exigencias de los arts. 93 y 214 de la CP deben ser tenidos en cuenta para ejercer el control de constitucionalidad de las leyes y, por ende, del Congreso. (art 241 numerales 4 y 10 de la C.P.)

Señala Bronstein (2014) que desde el año 1921 cuando se adoptó el convenio 11 sobre libertad sindical para los trabajadores de la agricultura, la Conferencia de la OIT se empezó a preocupar por la necesidad de crear normas vinculantes en materia de negociación colectiva. Fue el año de 1948 cuando se adoptó el convenio 87, y un año 
después se aprobó el convenio 98, ambos sobre sindicación y negociación colectiva.

El comité sindical de la OIT ha señalado con respecto al artículo 4 del convenio 98, que la libertad sindical exige que los trabajadores puedan libremente negociar todo lo que tenga que ver con las condiciones de trabajo.

El convenio 151 fue adoptado en 1978 y el convenio 154 en 1981. En Colombia la Corte Constitucional elevó a nivel de bloque de constitucionalidad los cuatro convenios mencionados en precedencia a través de la sentencia C-349 de 2009.

En igual sentido la Corte Suprema de Justicia según la sentencia STL10962-2016.

En cambio, a través de la Sentencia 2008-00408/0330-2012 de mayo 11 de 2017, el Consejo De Estado, Sección Segunda, Subsección "B", Rad.: 68001-23-31-000-2008-0040802(0330-12), Actor: Universidad Industrial de Santander - UIS, dijo concretamente:

En efecto, la Corte Constitucional no solo no determinó explícitamente que los convenios 151 y 154 de la OIT se constituyeran en normas de raigambre constitucional, sino que mediante la Sentencia C-1234 de 2005 señaló categóricamente que estaban integradas al ordenamiento jurídico interno, por tanto, es dable concluir, a contrario sensu, que si hacen parte de la legislación interna no hacen parte del bloque de constitucionalidad.

Al respecto, es importante resaltar, como lo señaló la Sala en sentencia del 27 de abril de 2017, que las disposiciones contenidas en el Convenio 154 de la OIT, y las normas que de él se derivaren hacen parte del orden jurídico interno y, por tanto, no integran el bloque de constitucionalidad ni en sentido estricto, ni en sentido lato, de tal suerte que no se constituyen en parámetro de comparación con superior jerarquía a las de la ley ordinaria, no pudiendo ser equiparables a aquellas de raigambre constitucional.

En lo atinente a las recomendaciones de la OIT como la 159, y los convenios 151 y 154 para quienes no los consideran integrantes del bloque estricto de constitucionalidad, constituyen en todo caso fuente vinculante al interpretar los distintos principios y normas constitucionales en materia de negociación colectiva por expresa disposición de los artículos 93 inciso segundo y $94 \mathrm{CP}$.

\section{El mayor margen de configuración que tiene la convención colectiva con respecto al acuerdo colectivo}

El artículo 467 del CST señala que la convención colectiva es un negocio jurídico por medio del cual tanto empleadores como trabajadores regulan todas las condiciones que han de regir los contratos de trabajo durante su vigencia. De la lectura se infiere que las convenciones colectivas parecieran tener limitaciones en cuanto a la regulación pensional, por tratarse de cuestiones por fuera de la vida activa del trabajador.

Con el acto legislativo 01 de 2005 el constituyente superó cualquier elucubración al respecto, al señalar que las convenciones colectivas de todo tipo que regulan pensiones extralegales quedan vigentes en todo caso hasta el 31 de julio del año 2010 .

La Corte Suprema de Justicia a través de la sentencia SL 12498-2017, apoyada en la sentencia SU-555 de 2014 de la Corte Constitucional, señala que las convenciones celebradas antes del 25 de julio de 2005 conservan su vigencia, pero las prórrogas se regulan así:

Con relación a la segunda parte de este parágrafo transitorio: "En los pactos, convenciones o laudos que se suscriban 
entre la vigencia de este Acto Legislativo y el 31 de julio de 2010, no podrán estipularse condiciones pensionales más favorables que las que se encuentren actualmente vigentes. En todo caso perderán vigencia el 31 de julio de 2010" la Constitución también protege las expectativas de aquellos que cumplieron los requisitos para acceder a la prestación convencional entre el 29 de julio de 2005 y el 31 de julio de 2010, como consecuencia de las prórrogas de aquellas convenciones que se encontraban vigentes antes de la entrada en vigor del Acto Legislativo. Prórrogas que conservarán los mismos beneficios que venían rigiendo, teniendo en cuenta la prohibición de pactar condiciones más favorables.

En cuanto a las condiciones laborales de la vida activa del trabajador, el código sustantivo del trabajo trae unas prestaciones mínimas y un salarió mínimo a partir del cual el empleador puede mejorar las condiciones de sus trabajadores, arts. 13, 127 y 128. Igualmente existe plena libertad para configurar lo relacionado con aspectos disciplinarios y garantías sindicales, art 108 CST.

En caso de que las partes, sindicato de trabajadores particulares u oficiales y empleadores, art 414 CST, no se pongan de acuerdo, a través de un tribunal de arbitramento se pueden consensuar de manera indirecta las cláusulas en que hubo disenso siempre y cuando hayan hecho parte del pliego de peticiones y se hubieran discutido durante la etapa de arreglo directo, art 458 CST.

En caso de que alguna de las partes considere que el tribunal de arbitramento tomó decisiones que son de resorte exclusivo de la ley, como la modalidad del contrato, o sobre asuntos no sometidos a negociación en la mesa de negociaciones, solicitará la anulación del laudo arbitral. La Corte Suprema de Justicia solo podrá anular o validar o devolver el expediente para que se resuelvan asuntos que hubiera definido el tribunal, pero en ningún caso puede reconocer derechos, art 142 y 143 CPLySS. Esto dijo la corte en la Sentencia SL 10179-2015:

Lo dicho debe verse desde la óptica del recurso de anulación, pues, ya se ha dicho, éste tiene por objeto la anulación de las disposiciones del laudo cuando, en decir del recurrente, su existencia afrenta la Constitución, la ley laboral, la convención colectiva de trabajo, la competencia del Tribunal o la equidad; en tanto que, la interpretación, aplicación o integración de las dichas disposiciones compete no a su existencia o validez, sino a la eficacia de las mismas en el plano de las relaciones laborales que regula, de forma que, no es el recurso de anulación el mecanismo idóneo para su cuestionamiento y definición, sino, en defecto del sentido que a ellas dieren las partes de consuno, el proceso ordinario laboral, pues es allí donde debe definirse tal tipo de controversias.

Ahora, si las anteriores convenciones colectivas no tuvieron fecha de duración, la ley presume un plazo de vigencia por términos sucesivos de seis en seis meses. En caso de que el sindicato no haya iniciado el conflicto colectivo 60 días antes de la fecha de vencimiento de la convención colectiva, la misma se entiende prorrogada de seis en seis meses, arts. 477 y 478 CST.

Finalmente, como la convención colectiva se extiende y beneficia a los demás trabajadores si el sindicato agrupa siquiera una tercera parte, quienes se vean beneficiados de la misma deben pagar las cuotas de mantenimiento, arts. $471 \mathrm{y}$ 400 CST.

Todas esas normas que regulan las convenciones colectivas no se pueden emigrar a los acuerdos colectivos, pues la vinculación de los empleados públicos es legal y reglamentaria, art $122 \mathrm{CP}$.

El constituyente en los artículos 55 y 39 señala que el funcionamiento de los sindicatos 
se debe sujetar a la ley y a los principios democráticos. La primera limitante directa la consagra la Constitución Política al prohibirles a los miembros de la Fuerza Pública formar sindicatos, pues negociar con quien tiene el poder de las armas resulta peligroso para el Estado de derecho.

En igual sentido el convenio 154 de la OIT le da vía libre a cada Estado para que regule lo relacionado con las fuerzas militares y la policía. El convenio 151 que regula el derecho de negociación colectiva del empleado público le permite a cada Estado regular a su manera el derecho de sindicación de los empleados de libre nombramiento y remoción o quienes tienen poder decisorio lo mismo que a la fuerza pública. Dice textualmente en el artículo primero:

2. La legislación nacional deberá determinar hasta qué punto las garantías previstas en el presente Convenio se aplican a los empleados de alto nivel que, por sus funciones, se considera normalmente que poseen poder decisorio o desempeñan cargos directivos o a los empleados cuyas obligaciones son de naturaleza altamente confidencial.

3. La legislación nacional deberá determinar asimismo hasta qué punto las garantías previstas en el presente Convenio son aplicables a las fuerzas armadas y a la policía.

A nivel legislativo, el decreto 160 de 2014 al regular el derecho de asociación y negociación del empleado público, actuando conforme al convenio 151 de la OIT, señaló:

Artículo $2^{\circ}$. Campo de aplicación. El presente decreto se aplicará a los empleados públicos de todas las entidades y organismos del sector público, con excepción de:

a). Los empleados públicos que desempeñen empleos de alto nivel político, jerárquico o directivo, cuyas funciones comporten atribuciones de gobierno, representación, autoridad o de conducción institucional, cuyo ejercicio implica la adopción de políticas públicas;

b). Los trabajadores oficiales;

c). Los servidores de elección popular o los directivos elegidos por el Congreso o corporaciones territoriales, $\mathrm{y}$,

d). El personal uniformado de las Fuerzas Militares y de la Policía Nacional.

En cuanto al contenido u objeto de negociación, se excluyó del acuerdo colectivo la estructura del Estado y la organización de las entidades públicas; las competencias de dirección, administración y fiscalización del Estado; la manera de acceder a la carrera administrativa; la función disciplinara de las autoridades públicas; y la potestad subordinante en los cargos con vinculación legal y reglamentaria, art 5.

Desde la expedición del código sustantivo del trabajo, el legislador en el artículo 414 delimitó la negociación colectiva de los empleados públicos a simples concertaciones o derechos de petición respetuosos sobre: estudio de las características de las distintas profesiones, las condiciones de trabajo, asesoría a los miembros del sindicato, representar en juicio a los miembros del sindicato en asuntos económicos, peticiones para mejorar los métodos de trabajo, promover la educación de sus miembros, prestarles apoyo ante las contingencias de la desocupación y la enfermedad, fomentar la creación de cooperativas y la adquisición de inmuebles y muebles para el desarrollo del objeto social.

Todas esas actividades en realidad dejaban al garete cualquier función tuitiva del sindicalista público, pues a la administración le bastaba con indicar que no existían condiciones económicas o la oportunidad y conveniencia no se daban en determinado momento, con lo que cualquier petición terminaba en simple prosa. 
El convenio 160 de 2014 es una superación al artículo 414 del CST, sin embargo, es mucho lo que falta para que los acuerdos colectivos en realidad sean tomados en serio al momento de definir políticas legislativas y reglamentarias por parte del gobierno central. En el caso de la negociación sobre salarios y prestaciones sociales y beneficios extralegales, se requiere de una ley que lo permita.

Igualmente no es viable hacer descuentos de cuotas sindicales si el empleado público no lo autoriza así se esté beneficiando del acuerdo colectivo, decreto 1848 de 1969, art 93, a diferencia del trabajador oficial, decreto ley 2351 de 1965, art 39.

Permítanme repetir en lo que sigue, lo que le expresé a la CRQ: La competencia y el presupuesto son, entonces, las grandes limitantes que impiden que a través de acuerdos colectivos se modifiquen normas constitucionales como el artículo 150 numeral 19 literales e) y f), las cuales le ordenan al Congreso dictar leyes marco para que el gobierno regule los salarios y prestaciones sociales de los empleados públicos, lo que efectivamente realiza a través de decretos sin sobrepasar en todo caso el marco general configurado en la ley 4 de 1992.

Permitir que un acuerdo colectivo modifique competencias constitucionales es quebrar el eje axial de la Constitución o elementos definitorios de identidad constitucional como es la separación de poderes. Precisamente la sustitución de la Constitución es la que impidió la tercera reelección presidencial, C-1040 de 2005, e hizo nugatorios los acuerdos de La Habana que le impedían al Congreso modificar los acuerdos de paz, pues eso era vaciar de funciones al órgano legislativo por antonomasia, C-699 de 2016.

En cambio, los particulares y las Empresas Industriales y Comerciales del Estado al vender servicios y competir en actividades propias de la economía de mercado, pueden pactar libremente los salarios y prestaciones sociales de los trabajadores oficiales. La función pública, en cambio, al construir la planta de personal, debe realizar un estudio técnico y de conformidad presupuestal que pende, no de la venta de servicios, sino del sistema fiscal. El mismo artículo 150 numeral 10 le impide al Presidente de la República decretar impuestos, lo que en este caso sería necesario para financiar las nuevas cargas salariales y prestacionales extralegales.

Ante ello, la Constitución Política en su artículo 55 permite que la ley construya excepciones al derecho a la negociación colectiva. Igualmente, la misma Constitución Política, art 150, señala que lo relacionado con salarios y prestaciones sociales no son objeto de convenio colectivo. Reza la norma:

"ARTÍCULO 150: Corresponde al Congreso
hacer las leyes, por medio de ellas ejerce las
siguientes funciones: (...)

19. Dictar las normas generales, y señalar en ellas los objetivos y criterios a los cuales debe sujetarse el Gobierno para los siguientes efectos: (...)

e) Fijar el régimen salarial y prestacional de los empleados públicos, de los miembros del Congreso Nacional y de la Fuerza Pública.

f) Regular el régimen de prestaciones sociales mínimas de los trabajadores oficiales.

g) Estas funciones en lo pertinente a prestaciones oficiales son indelegables en las corporaciones públicas territoriales y éstas no podrán arrogárselas..."

En los literales e) y f), de manera clara, sin usar un lenguaje indeterminado que pueda prestarse para concebir varias normas del mismo texto jurídico, la Constitución Política prohíbe a los directores de establecimientos públicos la celebración de 
acuerdos colectivos o convenciones colectivas con empleados públicos cuyo objeto jurídico sea la regulación de salarios y prestaciones sociales. Sobre el punto ha dicho el Consejo de Estado en sentencias como las siguientes:

Bogotá, D. C., veinticuatro (24) de mayo de dos mil dieciocho (2018). Radicado: 76001-23-31-000-2010-00963-02 Número interno: 1486-2017. Actor: Empresas Municipales de Cali - EMCALI E.I.C.E. E.S.P. Demandado: María Rubiela Contreras de Correa como sucesora procesal de Argemiro Correa Hoyos. Acción: Nulidad y Restablecimiento del Derecho - Decreto 01 de 1984 Asunto: Empleados públicos - Niega la convalidación prevista en el artículo 146 de la Ley 100 de 1993.

En este sentido, la fijación del régimen salarial y prestacional de los empleados públicos es una competencia que la Constitución y la ley reservaron de manera exclusiva al Gobierno Nacional, con observancia de los parámetros dados por el Congreso de la República, en virtud de los cuales es claro que no es dable a otro organismo arrogarse dicha facultad. Siendo así, resultan ilegales las normas de carácter local, como ordenanzas, acuerdos municipales, resoluciones o acuerdos de establecimientos públicos bien sean nacionales o del orden departamental, que regulen la materia y las convenciones colectivas en las que se consagren prerrogativas contra legem.

Igualmente dijo en un proceso en donde la Universidad Nacional -que tiene régimen propiohabía creado unas prestaciones sociales a favor de su personal administrativo:

Sentencia 2011-00151 del 5 de diciembre de 2013, ref: Exp. 170012331000201100151 01, Número interno: 1846-2013, Consejera Ponente: Dra. Bertha Lucía Ramírez de Páez (E)
Así las cosas, a los empleados públicos de las entidades territoriales, incluyendo a los docentes de las universidades públicas, no les asiste derechos adquiridos sobre las prestaciones sociales que por fuera de lo previsto en la Constitución y en la ley les fueron concedidas a través de acuerdos o cualquier acto administrativo que no haya sido expedido por el Gobierno Nacional, debido a la falta de competencia de los órganos que los profirieron $\mathrm{y}$, por tanto, dichos derechos no se consideran adquiridos con justo título ni conforme a las normas superiores, por lo que tales entidades pueden invocar válidamente la excepción de inconstitucionalidad prevista en el artículo $4^{\circ}$ de la Constitución Política para no seguir reconociendo y pagando prestaciones sociales que no sean las estrictamente legales.(...).

El legislador, conforme a la permisión del artículo 55 de la Constitución Política, expidió la ley 411 de 1997 aprobatoria del convenio 151 de la OIT, la cual fue reglamentada a través del decreto 160 de 1994 que prohíbe expresamente regular a través de acuerdos colectivos el régimen salarial y prestacional del empleado público siguiendo los parámetros del artículo 150 constitucional. Reza el decreto sobre el contenido de los acuerdos:

Artículo $1^{\circ}$. Objeto. El presente decreto tiene por objeto regular el procedimiento para la negociación exclusivamente de las condiciones de empleo, entre las entidades y autoridades públicas competentes y las organizaciones sindicales de empleados públicos.

En cuanto a la implementación de los acuerdos, el decreto 160 de 2014 reitera el respeto por las competencias constitucionales.

Artículo 14.Cumplimiento eimplementación del acuerdo colectivo. La autoridad pública competente, dentro de los veinte (20) días hábiles siguientes a la suscripción del acta 
final, y con base en ésta, expedirá los actos administrativos a que haya lugar, respetando las competencias constitucionales y legales. (Rayas fuera de texto)

Al expedir el decreto 160 de 2014, el gobierno fijó unas restricciones que se avienen al texto constitucional por lo que no podría pensarse en una extralimitación de funciones, pues aunque está reglamentando el convenio 151 de la OIT -aprobado a través de la ley 411-el cual no contiene restricciones negociables entre los sindicatos de empleados públicos y los empleadores, sí existen restricciones constitucionales, más concretamente el artículo 150 numeral 19 y el artículo 189 , los cuales señalan que el régimen salarial y prestacional será fijado unilateralmente por el gobierno, el Congreso, las Asambleas y Concejos. Igualmente, la capacidad presupuestal de las entidades públicas debe ser tenida en cuenta al momento de implementar la planta de personal, artículo 122 C.P.

El doctor Villegas (pág. 264) al interpretar el artículo 5 del decreto 160 de 2014 señala que las entidades empleadoras, entre las que se deben entender todas las que no sean el Congreso, asambleas, concejos, alcaldías y gobernaciones, carecen de competencia para dirimir a través de acuerdos colectivos asuntos relacionados con la "planta de empleo, régimen salarial y escalas de asignación básica mensual, prestaciones sociales, manual general de funciones, requisitos y competencias de los empleos, nomenclatura, clasificación y remuneración de empleos, instrumento general de evaluación del desempeño, carrera administrativa, concursos".

En materia salarial indica que esa negociación solo le compete al gobierno nacional y territorial. Las universidades públicas aunque tienen mayor autonomía deben respetar la ley marco 4 de 1992, termina diciendo el autor.

Por su parte, el Consejo de Estado trae como limitante a las negociaciones colectivas el que se circunscriban a la vida activa de la relación laboral, y ello porque a partir del acto legislativo 01 de 2005, no es factible regular lo relacionado con el sistema pensional a través de acuerdos colectivos.

Cumpliendo los cometidos del acuerdo 160 de 2014, por medio del decreto 309 de 2018, se cumplió el acuerdo colectivo celebrado entre el Presidente de la República y los representantes de las centrales y federaciones sindicales de empleados públicos, en cuanto al límite máximo salarial de los empleados públicos de las entidades territoriales. Para las entidades del orden nacional entre las que se mencionan las Corporaciones Autónomas, se expidió el decreto 330 de 2018. Esas negociaciones no pueden ser modificadas por ningún otro pliego de condiciones por expresa prohibición de los artículos 3 numeral tercero y 13 del decreto 160 de 1994.

\section{Lo que queda para negociar a través de acuerdos colectivos}

El decreto 160 de 2014 señala que solo se puede negociar lo relacionado con las condiciones de empleo y las relaciones entre las entidades públicas y las organizaciones sindicales, art 5 .

Ahora, ¿qué significa condiciones de empleo? En comienzo es todo; salarios y prestaciones sociales, solo que estas solo pueden ser negociadas con el poder central, como se hace con el salario mínimo. Para entender el significado de lo que queda de la expresión condiciones de empleo, se transcribe in extenso lo que ha dicho la Corte Suprema de Justicia en la sentencia SL16811.2017 al respecto:

Sobre el contenido de los acuerdos colectivos, los órganos de control de la Organización Internacional del Trabajo han adoctrinado: 
En los Convenios núms. 98, 151 y $154 \mathrm{y}$ en la Recomendación núm. 91 se centra el contenido principal de la negociación colectiva en las condiciones de trabajo y empleo, así como en la regulación de las relaciones entre los empleadores y los trabajadores y sus respectivas organizaciones. El concepto de «condiciones de trabajo» no sólo comprende las condiciones de trabajo tradicionales (jornada de trabajo, horas extraordinarias, períodos de descanso, salarios, etc.), sino también las cuestiones que las partes decidan contemplar libremente, como las que suelen incluirse en el ámbito de las condiciones de empleo en sentido estricto (ascensos, traslados, supresión de puestos sin preaviso, etc.). En la práctica, pese a que las condiciones de trabajo siguen siendo aspectos fundamentales de la mayoría de los convenios colectivos, la variedad de temas que en ellos se abordan ha ido ampliándose y refleja la evolución de las relaciones laborales. Es cada vez más frecuente que en los convenios se traten cuestiones como, por ejemplo, el número de personas contratadas, la seguridad y la salud, los procesos de reestructuración, la formación, la discriminación y las prestaciones complementarias de seguridad social. Los convenios también sirven a veces para institucionalizar procedimientos de recurso o mecanismos de solución de conflictos, y para prevenir huelgas. Por último, también pueden utilizarse, cuando sea conveniente, para que se tomen disposiciones en beneficio de los trabajadores, en particular en aras de su bienestar en el trabajo (médicos de empresa, economatos, contratos de préstamo, ayuda al alojamiento, etc.) $[\ldots]$

Igualmente, la corte, citando la Declaración de la OIT sobre la justicia social para una globalización equitativa (2008, ginebra, reunión 2012, pág. 94) señaló que la negociación colectiva no se puede limitar solo a los contenidos de los contratos de trabajo como salarios, prestaciones sociales, descansos, indemnizaciones y jornadas de trabajo, o a las relaciones sindicatos-empleadores, sino que todo fenómeno empresarial debe ser tenido en cuenta.

Da a entender la corte que todo lo relacionado con traslados, ascensos, reglas del debido proceso en procedimientos disciplinarios, etcétera, deben ser concebidos logrando un consenso con los grupos organizados de trabajadores en aras de lograr la cooperación y una mejor calidad de vida, lo que implicaría la obligación de confeccionar políticas públicas consensuadas. ¿Tanta democracia participativa podría facilitar la creación de un Estado caótico que, amarrado por la imposibilidad de finiquitar acuerdos, facilitaría el acceso al poder de grupos que auspician el incumplimiento de las reglas pre-establecidas?

\section{Protección del Ministerio del Trabajo a los acuerdos colectivos y su control judicial}

El artículo 485 del CST señala que compete al Ministerio del Trabajo la vigilancia y control de las normas contenidas en el código del trabajo. Como el artículo 3 señala que la parte colectiva del código se aplica a los sindicatos, trabajadores y empleadores del sector público y privado, le compete a dicha oficina del trabajo lo relacionado con los acuerdos colectivos.

La vigilancia y control se definen en el artículo 354 del CST al señalar de manera taxativa las conductas de los empleadores que se deben sancionar. Las mismas deben consistir en vulneración al derecho que tienen los trabajadores de pertenecer o retirarse de un sindicato, toda conducta que le impida al sindicato ejercer su derecho constitucional de confección libre de sus estatutos, negarse a recibir los negociadores de la organización sindical, o despedir o desmejorar a un empleado por pertenecer al sindicato. 
A través de la circular 0048 del 2 de julio de 2014, el Ministerio del Trabajo señaló sobre sus competencias como policía administrativa en materia del derecho a la negociación:

Las competencias señaladas que habilitan a este Ministerio mediante sus agentes para ejercer como policía administrativa en materia laboral, se encuentran previstas en el artículo 27 numeral 1 del Decreto 4108 de 2011 y el artículo $1^{\circ}$ de la Ley 1610 de 2013.

Igualmente, el artículo 486 modificado por la ley 584 señala que le queda prohibido al Ministerio del Trabajo declarar derechos individuales o definir controversias judiciales, pues la Constitución Política colombiana siempre ha protegido la separación de poderes impidiendo que una rama del poder público se inmiscuya en las funciones de otra. Dice la norma:

\section{Articulo 486. Atribuciones y sanciones. <Artículo subrogado por el artículo 41 del Decreto 2351 de 1965. El nuevo texto es el siguiente:>}

1. $<$ Numeral modificado por el artículo 20 de la Ley 584 de 2000. El nuevo texto es el siguiente:> Los funcionarios del Ministerio de Trabajo podrán hacer comparecer a sus respectivos despachos a los empleadores, para exigirles las informaciones pertinentes a su misión, la exhibición de libros, registros, planillas y demás documentos, la obtención de copias o extractos de los mismos. Así mismo, podrán entrar sin previo aviso, y en cualquier momento mediante su identificación como tales, en toda empresa con el mismo fin y ordenar las medidas preventivas que consideren necesarias, asesorándose de peritos como lo crean conveniente para impedir que se violen las disposiciones relativas a las condiciones de trabajo y a la protección de los trabajadores en el ejercicio de su profesión y del derecho de libre asociación sindical. Tales medidas tendrán aplicación inmediata sin perjuicio de los recursos y acciones legales consignadas en ellos. Dichos funcionarios no quedan facultados, sin embargo, para declarar derechos individuales ni definir controversias cuya decisión esté atribuida a los jueces, aunque sí para actuar en esos casos como conciliadores.

Es decir, el Ministerio del Trabajo puede sancionar los incumplimientos estipulados en los acuerdos colectivos, siempre y cuando lo acordado respete las restricciones contenidas en el decreto 160 de 2014. Cualquier diferencia al respecto debe ser dilucidada por un juez de la república por expresa disposición del artículo 486 del CST.

En la circular conjunta 100-01-2017 del 28 de febrero de 2017 emitida entre el Ministerio del Trabajo y la Función Pública, se dijo:

En la concertación del pliego los negociadores deben tener en cuenta sus competencias constitucionales y legales $\mathrm{y}$ tener claro que las materias salariales y prestacionales deben ser presentadas en la mesa nacional, en la cual se discute el pliego unificado de contenido general o común.

Como lo acordado bilateralmente en el acuerdo colectivo requiere de la decisión unilateral de la administración a través de una ley o un acto administrativo, mientras ello no ocurra, no es viable acudir a la justicia.

Sobre el punto dijo la función pública citando a la Corte Constitucional en el Concepto 128951 de 2014:

Puede ocurrir que por las características especiales del Acuerdo se hayan pactado obligaciones complejas que estén aún pendientes de ejecutar a la terminación del mismo; puesto que hay casos en los que alguna de las entidades, no obstante haber cumplido con el objeto pactado, precise cumplir compromisos que deban satisfacer con cargo a sus apropiaciones. 
Por consiguiente, si la entidad estaba comprometida a realizar actividades o gestiones para permitir el goce de beneficios acordados entre las partes que no pudo realizar en el término de ejecución del Acuerdo por factores externos a su voluntad, bien puede solicitar la ampliación del plazo para que en este nuevo plazo de vigencia tenga la oportunidad de proceder conforme con lo convenido, circunstancia que no es dable predicar vía trámite de concertación entre las partes cuando el Acuerdo ha perdido su vigencia.

Respecto a considerar una prórroga automática ante el silencio de las partes como acontece como una Convención Colectiva, debemos advertir que ésta aplica para los particulares y los trabajadores oficiales en la medida en que el vínculo laboral es contractual y las estipulaciones laborales surgen de la autonomía de la voluntad, mientras que para los empleados públicos el vínculo es reglado y las condiciones laborales se establecen por ley.

El doctor VILLEGAS (2014) también considera que la eficacia del acuerdo colectivo pende de la capacidad presupuestaria, lo que implica incluir lo acordado en un acto administrativo para ser exigible.

Un ejemplo: si el acuerdo colectivo se celebró con fecha de mayo 30/14, el término de vigencia solo debe ser hasta el 31 de diciembre, pero no del año fiscal/14 durante cuya ejecución presupuestal se celebró el acuerdo colectivo, sino hasta el 31 de diciembre de la ejecución presupuestal del año siguiente, 2015, en el entendido que para esa ejecución presupuestal 2015 hubo la oportunidad en el 2014 de incluir las partidas necesarias para el cumplimiento/ pago del acuerdo colectivo. (pág. 341)

Sobre el control judicial ha dicho el Consejo de Estado en el proceso de Rad.: 68001-23-31-0002008-00408-02(0330-12), Actor: Universidad
Industrial de Santander - UIS:

En el anterior orden de ideas, queda claro para la Sala que no es objeto de la Jurisdicción de lo Contencioso Administrativo el control de legalidad o de constitucionalidad de las convenciones colectivas de trabajo, y que es facultad de las partes dar por terminados o modificar los acuerdos alcanzados de manera bilateral y concertada, mediante los mecanismos que consagra el Código Sustantivo del Trabajo y que responden a la naturaleza misma de la negociación colectiva como derecho social amparado, respaldado y garantizado por las normas constitucionales y legales del país, incluidas, por supuesto, aquellas que hacen parte del bloque de constitucionalidad y legalidad.

No obstante lo anterior, la Sala considera que en caso de contradicción entre un acuerdo logrado a través de una negociación colectiva y una norma constitucional, en virtud de la supremacía de la Constitución Política sobre cualquier otra norma de inferior jerarquía (C.N., art. $4^{\circ}$ ), es dable que los jueces de la República inapliquen tal convenio y puedan anular los actos administrativos particulares que en virtud de tal convención se llegaron a expedir a favor de los trabajadores beneficiados con la negociación, máxime si se trata de convenciones colectivas de empleados públicos, donde el derecho a la libre concertación de las condiciones laborales no es absoluto. (Rayas fuera de texto).

Sintetizando, aunque los acuerdos colectivos no son demandables directamente, una vez que el empleado público solicita por vía judicial el reconocimiento de un derecho contenido en el acuerdo colectivo y prohijado a través de un acto unilateral de la administración llámese ley o acto administrativo, art 14 del decreto 160 de 2014, el juez debe realizar un control de legalidad para ordenar o no el cumplimiento de la pretensión, pues lo ilegal por inveterado y reiterado que sea no genera derechos. 


\section{Acuerdos colectivos de algunas instituciones del Estado}

Con el sindicato de docentes -FECODE- el gobierno nacional a través de acuerdos colectivos reguló la jornada única, la recuperación del tiempo de estudio que no se prestó por la huelga de docentes, todo lo relacionado con el ingreso y permanencia de niños niñas y adolescentes en el sistema educativo en aras de impedir la deserción. Esos acuerdos se implementaron a través de las resoluciones 1177, 2105, 13995 y 18552 de 2017.

Ante las limitantes existentes para confeccionar acuerdos colectivos, algunas entidades han regulado de consuno el régimen de estímulos consagrado a partir del artículo 69 del decreto 1227 de 2005, y el régimen de incentivos para los mejores trabajadores y grupos de trabajo.

Sin embargo, muchas entidades siguen sin concertar. La Procuraduría General de la Nación, a través de la resolución 573 del 1 de noviembre de 2017, reguló de manera unilateral el plan de incentivos no pecuniarios de sus empleados públicos. Para ello abrió procesos de elección del mejor empleado de carrera y del mejor grupo de trabajo. Como incentivos se crearon: concesión de becas, acceso a capacitación no formal, comisión de estudios, ingreso preferente para cursos de formación, publicación de trabajos o investigaciones, encargos o comisiones hasta por seis meses, comisiones especiales, entre otros.

Por medio de la resolución 574 del 1 de noviembre de 2017, la Procuraduría General de la Nación creó de manera unilateral el plan integral de bienestar social, artículo 2.2.10.2 del decreto 1083 de 2015.

El Ministerio de Relaciones Exteriores por resolución 7980 del 20 de septiembre de
2018, de manera unilateral creó el sistema de incentivos pecuniarios y no pecuniarios. Como incentivos no pecuniarios estableció becas, programas de turismo social, financiación de investigaciones y publicación de trabajos. Los estímulos pecuniarios los estableció únicamente para el mejor grupo de trabajo.

El Consejo de Estado al considerar que los estímulos de los empleados públicos son taxativos incentiva esas prácticas unilaterales. Dijo textualmente al citar el artículo 69 del decreto 1227 de 2005:

Concepto 2334 de noviembre 27 de 2017, Consejo de Estado, Sala de Consulta y Servicio Civil, Rad.: interna: 2344, $\mathrm{N}^{\mathrm{o}}$ único: 11001-03-06-000-2017-00096-00, Consejero Ponente: Dr. Édgar González López

Por otra parte, el Decreto 1083 del 26 de mayo de 2015, "Por medio del cual se expide el Decreto Único Reglamentario del Sector de Función Pública", dedica el título 10 al "Sistema de estímulos", dentro del cual es preciso destacar las siguientes normas:

El artículo 2.2.10.1, el cual establece que tales beneficios se deben implementar por medio de programas de bienestar social. Dice así:

"ART. 2.2.10.1. -Programas de estímulos. Las entidades deberán organizar programas que incentiven el desempeño eficaz y el compromiso de sus empleados. Los premios al rendimiento se implementarán a través de programas de bienestar social.

(D. 1227/2005, art. 69)".

Conforme se advierte en la norma anterior, esta no incluye dentro de los programas de protección y servicios sociales de las entidades públicas, en coordinación con las entidades de seguridad social, la contratación 
de seguros y por ende, del seguro de vida colectivo.

La Corte Suprema de Justicia sala laboral en el caso de los beneficios preceptuados en un laudo arbitral pero cubiertos por el sistema general de seguridad social, ha dispuesto su nulidad al considerar que un arbitraje no puede reconocer derechos que el sistema de salud ya viene cubriendo. Solo si las partes de común acuerdo lo hacen en la convención colectiva es viable mejorar las prestaciones sociales de ley. En el caso de los empleados públicos ello no es posible por involucrar el presupuesto público, lo que impide imponer dicha carga sin la anuencia del ejecutivo. Esto dijo al respecto la corte en la sentencia SL8693-2014:

Entre tanto, el que impuso a la empresa la obligación de cubrir el valor de los exámenes de citología a las esposas y madres de los trabajadores, sí invade el terreno propio de la ley de seguridad social en salud, pues su cobertura comprende esta clase de dictámenes médicos, en tanto se prevé que la cónyuge y madre de los trabajadores de la empresa afiliados a dicho sistema, según el caso, son beneficiarias de éstos y en esa medida su plan obligatorio de salud le cubre aquellos exámenes conforme a la Resolución 5261 de 1994 del Ministerio de la Protección Social.

Igual situación se presenta del artículo 23, en tanto la norma está ordenando el pago de una suma adicional a la que prevé el sistema de seguridad social cuando un trabajador sufre un accidente de trabajo, en particular el artículo 7 del Decreto Ley 1295 de 1994 que ordena el pago de subsidio por incapacidad temporal e indemnización por incapacidad permanente parcial, entre otras prestaciones.

Se anularán los artículos 20 y 23.

Es decir, el régimen de estímulos que podría tener mayor margen de configuración entre la administración y el sindicato de empleados públicos, se ha visto diezmado por las diferentes interpretaciones de las altas cortes.

Por medio del concepto 78641 de 2016, el Departamento Administrativo de la Función Pública absolvió el siguiente problema jurídico: ¿Es viable reconocer a los empleados de la entidad un bono navideño por $\$ 100.000$ como parte de los programas de bienestar social?

Para resolver el interrogante dijo:

De acuerdo con las disposiciones transcritas del Decreto Ley 1567 de 1998, los programas de bienestar social que adelanten las entidades públicas deberán enmarcarse dentro del área de protección y servicios sociales y del área de calidad de vida laboral; dentro de los programas de protección y servicios sociales se deben estructurar programas mediante los cuales se atiendan las necesidades de protección, ocio, identidad y aprendizaje del empleado y su familia, para mejorar sus niveles de salud, vivienda, recreación, cultura y educación; programas que serán atendidos en forma solidaria y participativa por los organismos especializados, con el apoyo y la coordinación de cada entidad.

Indicó, además, que cada año se deben apropiar las partidas presupuestales requeridas para cumplir todo tipo de obligación surgida de los programas de bienestar social, con lo que se impone la necesidad de incorporar en cada acuerdo colectivo, de manera expresa, las conquistas sociales de acuerdos colectivos anteriores, pues a diferencias de las convenciones colectivas que incorporan automáticamente anteriores derechos laborales así no se expresen en la nueva convención colectiva, en el caso de los acuerdos colectivos, cada año, es necesario realizar la apropiación presupuestal de acuerdo a la racionalización del gasto.

Y termina diciendo: 
Con fundamento en lo anterior y teniendo en cuenta el artículo 7 del Decreto 26 de 1998 : "Prohíbase ordenar, autorizar o efectuar fiestas, agasajos, celebraciones o conmemoraciones $u$ otorgar regalos con cargo al Tesoro Público, salvo en las actividades de bienestar social relacionadas con la celebración de Navidad de los hijos de los funcionarios", se considera que el regalo de un bono navideño en dinero para los empleados de la entidad derivado de los programas de bienestar social no es viable contemplarlo dentro de estos programas ya que los mismos van encaminados al beneficio y crecimiento personal del empleado (educación y capacitación), y a su vez al mejoramiento continuo de la entidad.

Por su parte el legislador señaló en el artículo 2 del decreto 2445 de 2000 que modificó el artículo 12 del Decreto 1737 de 1998:

“ARTÍCULO 12.- Está prohibida la realización de recepciones, fiestas, agasajos o conmemoraciones de las entidades con cargo a los recursos del Tesoro Público.

Se exceptúan de la anterior disposición, los gastos que efectúen el Departamento Administrativo de la Presidencia de la República, y, los gastos para reuniones protocolarias o internacionales que requieran realizar los Ministerios de Relaciones Exteriores, de Comercio Exterior y de Defensa Nacional y la Policía Nacional”.

\section{Conclusiones}

Los acuerdos colectivos y las convenciones colectivas de trabajo tienen regulaciones normativas diferentes dadas las competencias y financiación de las plantas de personal de las entidades del Estado. Mientras los empleos públicos tienen sus funciones detalladas en la ley o reglamento y sus emolumentos deben ser incorporados en el presupuesto, los trabajadores oficiales y particulares regulan sus funciones en cada contrato de trabajo. Además, al formar sus presupuestos de acuerdo con la rentabilidad que obtienen en la economía de mercado, pueden negociar con mayor libertad las condiciones económicas de sus trabajadores.

Tanto la Constitución Política como los convenios de la OIT aceptan limitantes en la negociación colectiva de los empleados públicos. Con fundamento en esas prerrogativas, el legislador expidió el decreto 160 de 2014 y preceptuó que la vinculatoriedad de los acuerdos colectivos pende de las decisiones unilaterales que realiza la administración sea por leyes ora por actos administrativos, debiendo, en todo caso, realizar un control de legalidad antes de implementar los acuerdos colectivos.

Igualmente, aunque el decreto 160 de 2014 permite regular las condiciones de empleo, las altas cortes han delimitado dichas facultades, pues al existir regulaciones y competencias de resorte exclusivo del Congreso o del Presidente, lo mismo que instituciones que hacen parte del eje axial, v.gr., el régimen de carrera o el régimen disciplinario, los acuerdos colectivos se han limitado a negociar el régimen de estímulos e incentivos.

Pero, como al reconocer los diferentes estímulos pecuniarios y no pecuniarios se hace necesario verificar la capacidad económica de la entidad y las políticas de ahorro fiscal del gobierno nacional, los mismos terminan siendo ofrecidos e impuestos por el empleador público. Aunado a ello, al regular el régimen de estímulos o bienestar, las altas cortes también han limitado su concesión a beneficios que no estén cubiertos por el régimen de seguridad social integral, con lo que el margen de protección que se puede lograr en tales negociaciones resulta inane.

\section{Referencias bibliográficas}

Bronstein, A. (2014). Derecho Internacional del Trabajo. Bogotá: Editorial Astrea/ 
Univ. De La Sabana.

Consejo de Estado. Concepto 2334 de noviembre 27 de 2017. Sobre los límites a la libertad negocial en materia de incentivos y estímulos.

Consejo de Estado. Sentencia 170012331000201100151 01, Número interno: 1846-(2013). Sobre la nulidad a una prima extralegal creada por la Universidad Nacional.

Consejo de Estado. Sentencia 68001-23-31000-2008-00408-02, Número interno: 0330-(2012). Para el Consejo de Estado los convenios 151 y 154 no hacen parte del bloque de constitucionalidad.

Consejo de Estado. Sentencia 68001-23-31000-2008-00408-02. Número interno 0330-(2012). Sobre el control de legalidad que debe hacer el juez al decidir derechos fundamentados en acuerdos colectivos.

Consejo de Estado. Sentencia 76001-23-31000-2010-00963-02 Número interno: 1486-(2017). Se anulan cláusulas de acuerdos colectivos por regular aspectos relacionados con salarios y prestaciones sociales.

Corte Constitucional. Sentencia C-284 (2015). Exequibilidad del artículo 4 de la ley 153 de 1887.

Corte Constitucional. Sentencia C-332 (2017). A través del juicio de sustitución se estudió el acto legislativo 01 de 2016.

Corte Constitucional. Sentencia C-349 (2009). $\mathrm{Se}$ resuelve la exequibilidad del artículo 448 del CST con respecto a los convenios 87,98 y 154 de la OIT y el preámbulo de la $\mathrm{CP}$.

Corte Constitucional. Sentencia C-466 (2008). Se resuelve la exequibilidad de normas del CST con respecto al art 39 de la CP y el convenio 87 de la OIT.

Corte Suprema de Justicia. Sentencia SL 10106-(2014). Sobre la aplicación del convenio 158 de la OIT como norma supletoria.

Corte Suprema de Justicia. Sentencia SL 10179-(2015). Sobre la competencia de los árbitros y la Corte Suprema de Justicia en la anulación de laudos arbitrales.

Corte Suprema de Justicia. Sentencia SL 12498-(2017). Sobre la vigencia de las pensiones convencionales.

Corte Suprema de Justicia. Sentencia SL 16811-(2017). Sobre la definición de la expresión condiciones de empleo desde los convenios de la OIT.

Corte Suprema de Justicia. Sentencia SL 8693-(2014). Sobre los límites a la libertad negocial en materia de incentivos y estímulos.

Corte Suprema de Justicia. Sentencia STL 10962-(2016). Sobre la aplicación del convenio 151 de la OIT como parte del bloque de constitucionalidad.

Guerrero, G. (2005). Derecho Colectivo del Trabajo. Bogotá: Leyer.

León, S. (2017). Los Casos Dificiles. La ponderación en la decisión del juez Laboral. Editorial Académica Española.

Nuñez, F. (2016). Derecho Colectivo del 
Trabajo. Legis.

Ortiz, A. (2015). Epistemología y Metodología de la Investigación Configuracional. Bogotá: Ediciones de la U.

Romero, E. (2013). Derecho de Asociación Sindical Convención Colectiva de los Servidores Públicos. En: Compendio Teórico Práctico de Derecho del Trabajo. Univ. Externado de Colombia.

Villegas, J. (2014). Negociación Colectiva y Sindicatos de Empleados Públicos. Univ. Externado de Colombia. 